\title{
Estimating the Thickness of Sedimentation within Lower Sokoto Basin, Nigeria, Using Both Spectral Depth Determination and Source Parameter Imaging
}

\author{
Kamba A.H*, Oladayo A.A and Fakai A.A
}

Department of Science Education, Kebbi State University of Science and Technology, Aliero, Nigeria

DOI: $10.36348 /$ sjet.2020.v05i03.005 $\quad$ | Received: 19.03 .2020 | Accepted: 27.03 .2020 | Published: 30.03 .2020

*Corresponding author: Kamba A. H

\section{Abstract}

The Total Aeromagnetic Data covering the study area was subjected to Spectral Depth Analysis and Source Parameter Imaging (SPI).The entire area was divided into nine sections. Spectral Depth Analysis was run for each of these nine sections. The result from Spectral Depth Analysis shows that a maximum depth of 3.174km was obtained around Konkoso in Sheet number 117 of the study area. Minimum depth estimates of $0.586 \mathrm{~km}$ were observed around the basement regions. Result obtained from the Source Parameter Imaging (SPI) method has its highest sedimentary thickness of about $2.4 \mathrm{~km}$ to $3 \mathrm{~km}$ in areas around Kaoje towards the central part up to around Konkoso in the southern part. The shallow sedimentary thickness was found predominantly around Shanga in the northeastern (NE) part, up to around Yelwa in the southeastern (SE) part. Geophysical implication of the result to oil and gas exploration in the area is briefly discussed.

Keywords: Aeromagnetic Data, Source Parameter Imaging (SPI), Geophysical implication, gas exploration.

Copyright @ 2020: This is an open-access article distributed under the terms of the Creative Commons Attribution license which permits unrestricted use, distribution, and reproduction in any medium for non-commercial use (NonCommercial, or CC-BY-NC) provided the original author and source are credited.

\section{INTRODUCTION}

The Earth and its contents have long been of concern to mankind. Man has tried to unravel its complexity and delve into its origin via various geophysical methods. The subsurface has been of particular concern to geoscientists, who seek to investigate it using diverse means, some for the purpose of having knowledge, while others do it for exploration of economic resources such as minerals and hydrocarbons. With the advances in technology and the need to have a clearer picture of the Earth subsurface and its contents, the Earth scientists have deemed it necessary to utilize the properties associated with Earth's interior. Geophysics involves the application of physical principles and quantitative physical measurements in order to study the Earth's interior. The analysis of these measurements can reveal how the earth interior varies both vertically and laterally, the interpretation of which can reveal meaningful information on the geological structures beneath [1]. By working at different scales, geophysical methods may be applied to a wide range of investigations from studies of the entire earth to exploration of a localized region of the upper crust for engineering or other purposes [2]. A wide range of geophysical methods exist for each of which there is an operative physical property to which the method is sensitive. The type of physical property to which a method responds clearly determines its range of application. For instance, magnetic method is very suitable for locating buried magnetic ore bodies because of their magnetic susceptibility. Similarly, seismic and electrical methods are suitable for locating water table, because saturated rock may be distinguished from dry rock by its higher seismic velocity and higher electrical conductivity [2]. In exploration for subsurface resources, the geophysical methods are capable of detecting and delineating local features of potential interest. Geophysical methods for detecting discontinuities, faults, joints and other basement structures, include the following: magnetic, seismic, resistivity, electrical, potential field, well logging, gravity, radiometric, thermal etc [3]. Some geophysical methods such as gamma- ray spectrometry and remote sensing measure surface attributes; others, such as thermal and some electrical methods are limited to detecting relatively shallow subsurface geological features. Most economic minerals, oil, gas, and groundwater lie concealed beneath the Earth surface, thus hidden from direct view. The presence and magnitude of these resources can only be ascertained by geophysical investigations of the subsurface geologic structures in the area. 

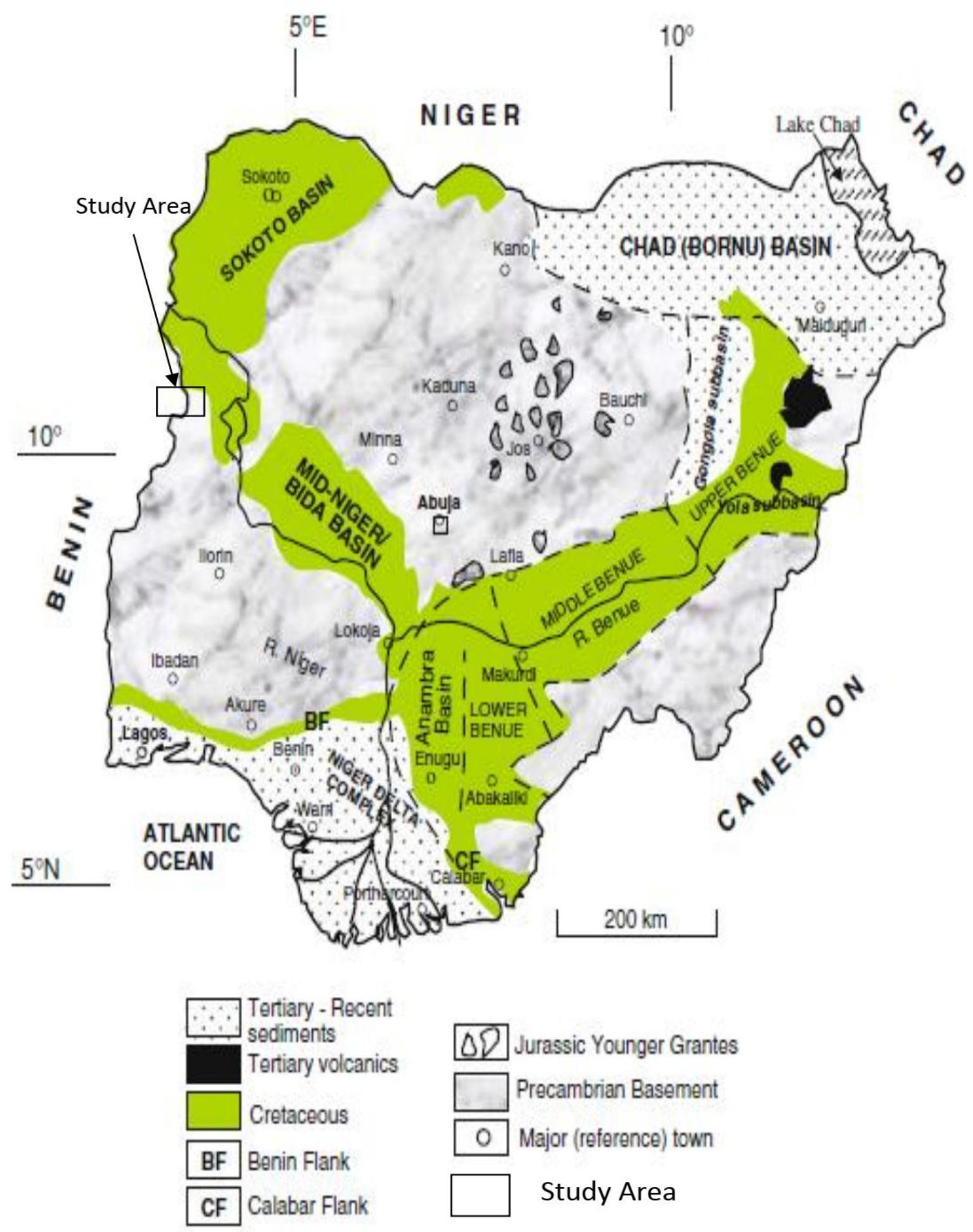

\section{$\Delta D$ Jurassic Younger Grantes}

Precambrian Basement

Major (reference) town

Study Area

Fig-1: Geologic Map of Nigeria Showing the Study Area [4]

\section{Location of the Study Area}

The study area (Figure-1) which lies in part of lower Sokoto Basin in North-Western Nigeria. The study area lies between longitudes $4^{0} .00^{\prime}-5^{0} .00^{\prime} \mathrm{E}$ and latitudes $10^{\circ} .500^{\prime}-11^{\circ} .500^{\prime} \mathrm{N}$ in the Sudan Sahel savannah region. The study area is covered by four maps obtained from the (NGSA). The four maps are Konkoso (sheet no: 117), Yelwa (sheet no: 118), Kaoje (sheet no: 95) and Shanga (sheet no: 96)

\section{MATERIALS AND METHODS}

The study area forms part of lower Sokoto sedimentary basin in northwest Nigeria and is covered by four (4) aeromagnetic maps. These maps were obtained from the Nigerian Geological Survey Agency (NGSA). The Agency carried out an airborne magnetic survey of substantial part of Nigeria between 1974 and 1980. The data were collected at a nominal flight altitude of $152.4 \mathrm{~m}$ along $\mathrm{N}-\mathrm{S}$ flight lines spaced 
Kamba A.H et al., Saudi J Eng Technol, March. 2020; 5(3): 120-127

approximately $2 \mathrm{~km}$ apart. The magnetic data collected were published in form of contour lines on $1 / 2$ degree aeromagnetic maps on a scale of $1: 100,000$. The magnetic values were plotted at $5 \mathrm{nT}$ (Nano Tesla) interval. The maps were numbered, and named according to the places covered and coordinates (longitude and latitudes) were written for easy reference and identification. The country was divided to a total of 340 sheets. The actual magnetic values were reduced by 25,000 gamma before plotting the contour map [5]. This means that the value of 25,000 gammas should be added to the contour values so as to obtain the actual magnetic field at a given point. A correction based on the International Geomagnetic Reference Field, (IGRF,) and epoch date January 1, 1974 was included in all the maps. The visual interpolation method that is the method of digitizing on grid layout was used to obtain the data from field intensity aeromagnetic maps covering the study area. The data from each digitized map were recorded in a 19 by 19 coding sheet which contains the longitude, latitude and the name of the town flown and the sheet number. The present study area covered four (4) maps numbered 95, 96,117,118. Surfer 11 software was used to import the dataset consisting of three columns (longitude, latitude and magnetic values). The composite map was produced using Oasis Montaj version 7.1.software

The procedures employed in this research include the following.

1. Production of Total Magnetic Intensity (TMI) map of the study area using MONTAJ software.

2. Spectral depth determination to buried magnetic rocks within the study area

3. Depth evaluation using Source Parameter Imaging.

\section{Source of Aeromagnetic Data}

The Data obtained from the Nigerian Geological Survey Agency (NGSA)

\section{Spectral Depth Analysis}

Determination of depths to buried magnetic rocks is among the principal applications of an aeromagnetic data. The depths are commonly computed from measurement made on the widths and slopes of an individual anomaly of theaeromagnetic profiles. The statistical approach has been found to yield good estimates of mean depth to basement underlying a sedimentary basin [6, 7]. Spector [8] and Spector and Grant [9], developed a depth determination method which matches two dimensional power spectral calculated from gridded total magnetic intensity field data with corresponding spectral obtained from a theoretical model. For the purpose of analyzing aeromagnetic data, the ground is assumed to consist of a number of independent ensembles of rectangular, vertical sided parallelepiped, and each is ensemble characterized by a joint frequency distribution for the depth (h) and length (b) and depth extent (t). In this work, the characteristics of the residual magnetic field are studied using statistical spectral methods. This is done by first transforming the data from space to the frequency domain and then analyzing their frequency characteristics. In the general case, the radial spectrum may be conveniently approximated by straight line segments, the slopes of which relate to depths of the possible layers $[9,6]$. The residual total magnetic field intensity values are used to obtain the two dimensional Fourier Transform, from which the spectrum is to be extracted from the residual values $\mathrm{T}(\mathrm{x}, \mathrm{y})$ consisting of $\mathrm{M}$ rows and $\mathrm{N}$ columns in $\mathrm{X}-\mathrm{Y}$. The two dimensional Fourier transforms is obtained as given in equation (2.1) above. The evaluation is done using an algorithm that is a two dimensional extension of the fast Fourier transform [10]. Next, the frequency intervals are subdivided into sub-intervals, which lie within one unit of frequency range. The average spectrum of the partial values together constitutes the redial spectrum of the anomalous field $[6,11,7]$. The logarithm of the energy values versus frequency on a linear scale was plotted and the linear segments located; the use of Discrete Fourier Transform introduced the problem of aliasing and the truncation effect (or Gibbs phenomenon). Aliasing was reduced by the digitizing interval used in the study. Three or two linear segments could be seen from the graphs. The first points on the frequency scale was ignored because the low frequency components in the energy spectrum are generated from the deepest layers whose locations are most likely in errors. Each linear segment groups points due to anomalies caused by bodies occurring within a particular depth. If the $\mathrm{z}$ is the mean depth of the layer, the depth factor for this ensemble of anomalies is exp (-2zk). Thus the logarithmic plot of the radial spectrum would give a straight line whose slope is $-2 z$. The mean depth of the burial ensemble is thus given as:

$$
Z=-\frac{m}{2}
$$

Where ( $\mathrm{m})$ is the slope of the best fitting straight line Equation 2 can be applied directly if the frequency unit is in radian per kilometre. If however, the frequency unit is in circle per kilometre, the corresponding relationship can be expressed as:

$$
Z=-\frac{m}{4 \pi}
$$

\section{Source Parameter Imaging (SPI)}

The Source Parameter Imaging (SPI) function is a quick, easy, and powerful method for calculating the depth of magnetic sources [12]. Its accuracy has been shown to be $+/-20 \%$ in tests on real data sets with drill whole control [12]. This accuracy is similar to that of Euler deconvolution, however SPI method has the advantage of producing a more complete set of coherent solution points and it is easier to use [12]. A stated goal 
Kamba A.H et al., Saudi J Eng Technol, March. 2020; 5(3): 120-127

of the SPI method [12] is that the resulting images can be easily interpreted an expert in the local geology. The SPI method [12] estimates the depth from the local wave number of the analytic signal. The analytical signal $\mathrm{A}_{1}(\mathrm{x}, \mathrm{z})$ is defined as [13]:

$A_{1}(x, z)=\frac{\partial M(x, z)}{\partial x}-j \frac{\partial M(x, z)}{\partial z}$

Where $(\mathrm{X}, \mathrm{Z})$ is the magnitude of the anomalous total magnetic field, $j$ is the imaginary number; $\mathrm{z}$ and $\mathrm{x}$ are Cartesian coordinates for the vertical direction and the horizontal direction respectively. Nabighian [13] showed that the horizontal and vertical derivatives comprising the real and imaginary parts of the $2 \mathrm{D}$ analytical signal are related as follows:

$$
\frac{\partial M(x, z)}{\partial x} \Leftrightarrow-\frac{\partial M(x, z)}{\partial z}
$$

Where $\Leftrightarrow d$ enoes a Hilbert transformation pair. The local wave number $\mathrm{k}_{1}$ is defined by as [12]:

$$
k_{1}=\frac{\partial}{\partial x} \tan ^{-1}\left[\frac{\partial^{2} M}{\partial^{2} z} / \frac{\partial^{2} M}{\partial x \partial z}\right]
$$

The concept of an analytic signal comprising second-order derivatives of the total field, if used in a manner similar to that used by Hsu et al., [14], the Hilbert transform and the vertical-derivative operators are linear, so the vertical derivative of (5) will give the Hilbert transform pair,

$$
\frac{\partial^{2} M(x, z)}{\partial x \partial z} \Leftrightarrow-\frac{\partial^{2} M(x, z)}{\partial^{2} z} \text {. }
$$

Thus the analytic signal could be defined based on second-order derivatives, $A_{2}(x, z)$, Where

$$
A_{2}(x, z)=\frac{\partial^{2} M(x, z)}{\partial x \partial z}-j \frac{\partial^{2} M(x, z)}{\partial^{2} z}
$$

This gives rise to a second-order local wave number $k_{2}$, where

$$
k_{2}=\frac{\partial}{\partial x} \tan ^{-1}\left[\frac{\partial^{2} M}{\partial^{2} z} / \frac{\partial^{2} M}{\partial x \partial z}\right]
$$

The first- and second-order local wave numbers are used to determine the most appropriate model and a depth estimate independent of any assumptions about a model. Nabighian [13] gives the expression for the vertical and horizontal gradient of a sloping contact model as:

$$
\begin{aligned}
& \frac{\partial M}{\partial z}=2 K F c \sin d \frac{h_{c} \cos (2 l-d-90)+x \sin (2 l-d-90)}{h_{c}^{2}+x^{2}} \\
& \frac{\partial M}{\partial z}=2 K F c \sin d \frac{x \cos (2 l-d-90)+h_{c} \sin (2 l-d-90)}{h_{c}^{2}+x^{2}}
\end{aligned}
$$

Where $\mathrm{K}$ is the susceptibility contrast at the contact, $\mathrm{F}$ is the magnitude of the Earth's magnetic field (the inducing field), $c=1-\cos ^{2} i \sin ^{2} \alpha, \alpha$ is the angle between the positive $\mathrm{x}$-axis and magnetic north, $i$ is the ambient-field inclination, $\tan 1=\operatorname{sini} / \cos \alpha, \mathrm{d}$ is the dip (measured from the positive x-axis), $h_{c}$ is the depth to the top of the contact and all trigonometric arguments are in degrees. The coordinate system has been defined such that the origin of the profile line $(\mathrm{x}=0)$ is directly over the edge. The expression for the magnetic-field anomaly due to a dipping thin sheet is [12]:

$$
M(x, z)=2 K F_{c w} \frac{h_{1} \sin (2 I-d)-x \cos (2 I-d)}{h_{c}^{2}+x^{2}}
$$

According to Reford [15], where $w$ is the thickness and $h_{1}$ the depth to the top of the thin sheet. The expression for the magnetic field anomaly due to a

$$
M(x, z)=2 K F S \frac{\sin i}{\sin I} \frac{\left(h_{h}^{2}-x^{2}\right) \cos (2 I-180)+2 x h_{h} \sin (2 I-180)}{\left(h_{c}^{2}+x^{2}\right)^{2}}
$$

Where $\mathrm{S}$ is the cross-sectional area and $h_{1}$ is the depth to the centre of the horizontal cylinder. Substituting equations (5), (6), (7) and (8) into the long horizontal cylinder is given according to Murthy and Mishra as [16]:

expression for the first- and second-order (i.e. equations (9) and (3) respectively), the local wavenumbers were obtained as 
Kamba A.H et al., Saudi J Eng Technol, March. 2020; 5(3): 120-127

$$
\begin{aligned}
& k_{1}=\frac{\left(n_{k}+1\right) h_{k}}{h_{k}^{2}+x^{2}} \\
& k_{2}=\frac{\left(n_{k}+2\right) h_{k}}{h_{k}^{2}+x^{2}}
\end{aligned}
$$

\section{ANALYSIS AND RESULTS Total Magnetic Intensity Map}

The colours shaded total magnetic intensity (TMI ) map of the study area is shown in Figure-2 while the contour map is shown in Figure-3. The colours shaded TMI map of the study area can be divided into three main sections, though minor depressions exist scattered all over area. The northern part of study area is predominantly characterized by high magnetic intensity values represented bypink-red colours, whereas the southern part is dominated by low and moderate TMI values represented by blue and green color respectively. The northern and southern parts of the study area were observed to be separated by a zone characterized by medium TMI values area depicted by yellow-orange colours. These high TMI values, which dominate the northern part of the study area, were interpreted to be caused probably by near surface igneous rocks of high values of magnetic susceptibilities. The low amplitudes (i.e. TMI values) where interpreted to be caused by sedimentary rocks of low magnetic susceptibilities or altered basement rocks. While the high TMI values were due to igneous and crystalline basement rocks. The contour map of the TMI values shows that the southeastern part (SE) and lower portion of the northeastern part (NE) are predominantly associated with short wavelength anomalies while the rest portion of the study area is dominated by long wavelength anomalies. The trends of the anomalies were observed along (NE-W), (E.W, N.S) and (NW-SW) directions.

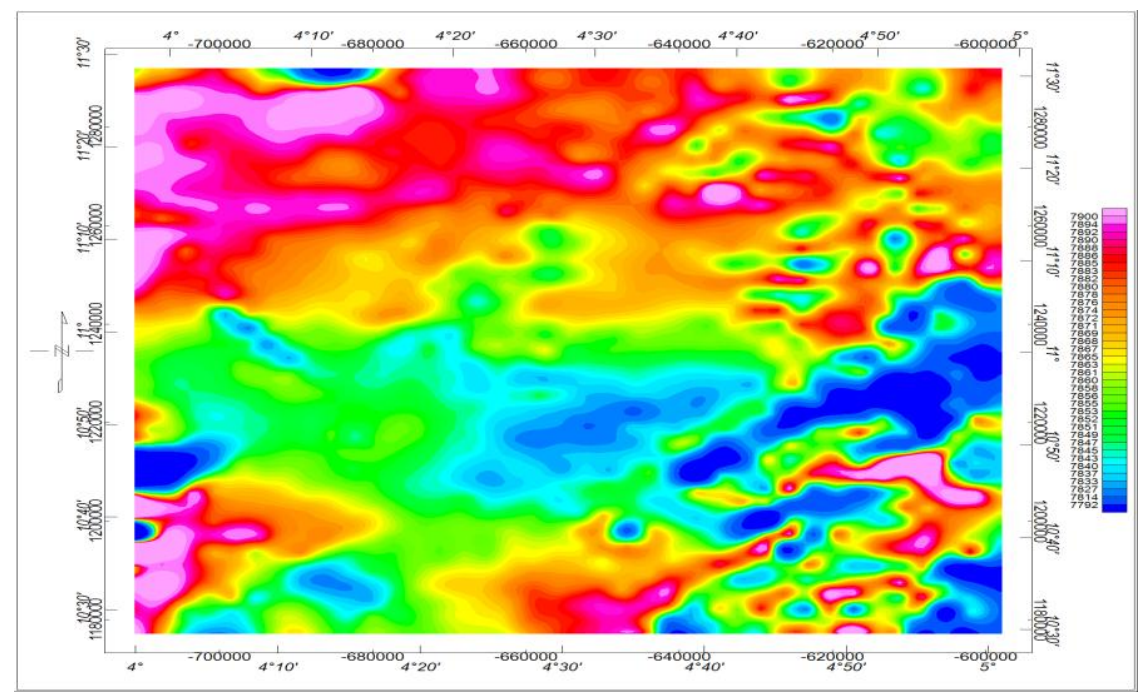

Fig-2: Total Magnetic Intensity (TMI) Map of the Study Area. To obtain the actual values $25000 \mathrm{nT}$ should be added to the colours shaded values

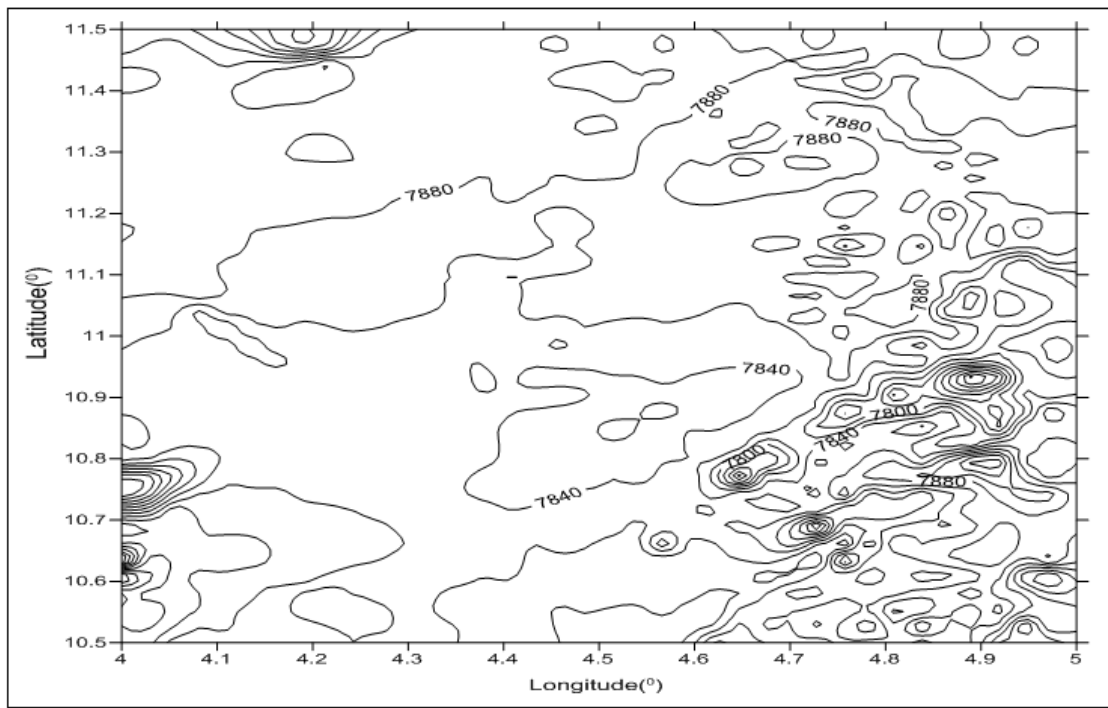

Fig-3: Total Magnetic Intensity Contours Map (Contour Interval, $20 \mathrm{nT}$ ). To obtain the actual values $25000 \mathrm{nT}$ should be added to the contour values 
Kamba A.H et al., Saudi J Eng Technol, March. 2020; 5(3): 120-127

\section{Source Parameter Imaging}

The colours shaded map of the depth estimates obtained from the (SPI) method is shown in Figure-4. Result obtained from the Source Parameter Imaging (SPI) method has its highest sedimentary thickness of about $2.4 \mathrm{~km}$ to $3 \mathrm{~km}$ in areas around Kaoje towards the central part up to around Konkoso in the southern part. The shallow sedimentary thickness was found predominantly around Shanga in the northeastern (NE) part, up to around Yelwa in the southeastern (SE) part.
The colours shaded map of the depth values also suggested that optimal depth valuesrange from 2.172 $\mathrm{km}$ to $2.396 \mathrm{~km}$ in and around Kaoje, in the northwestern (NW) part up to in and around Konkoso in the southwestern (SW) part. A depth value varies from $0.768 \mathrm{~km}$ to $2.396 \mathrm{~km}$. The shallow structures represented by red and pink clours, were observed to dominate the eastern part of the area while the deeper structure dominate the western part.

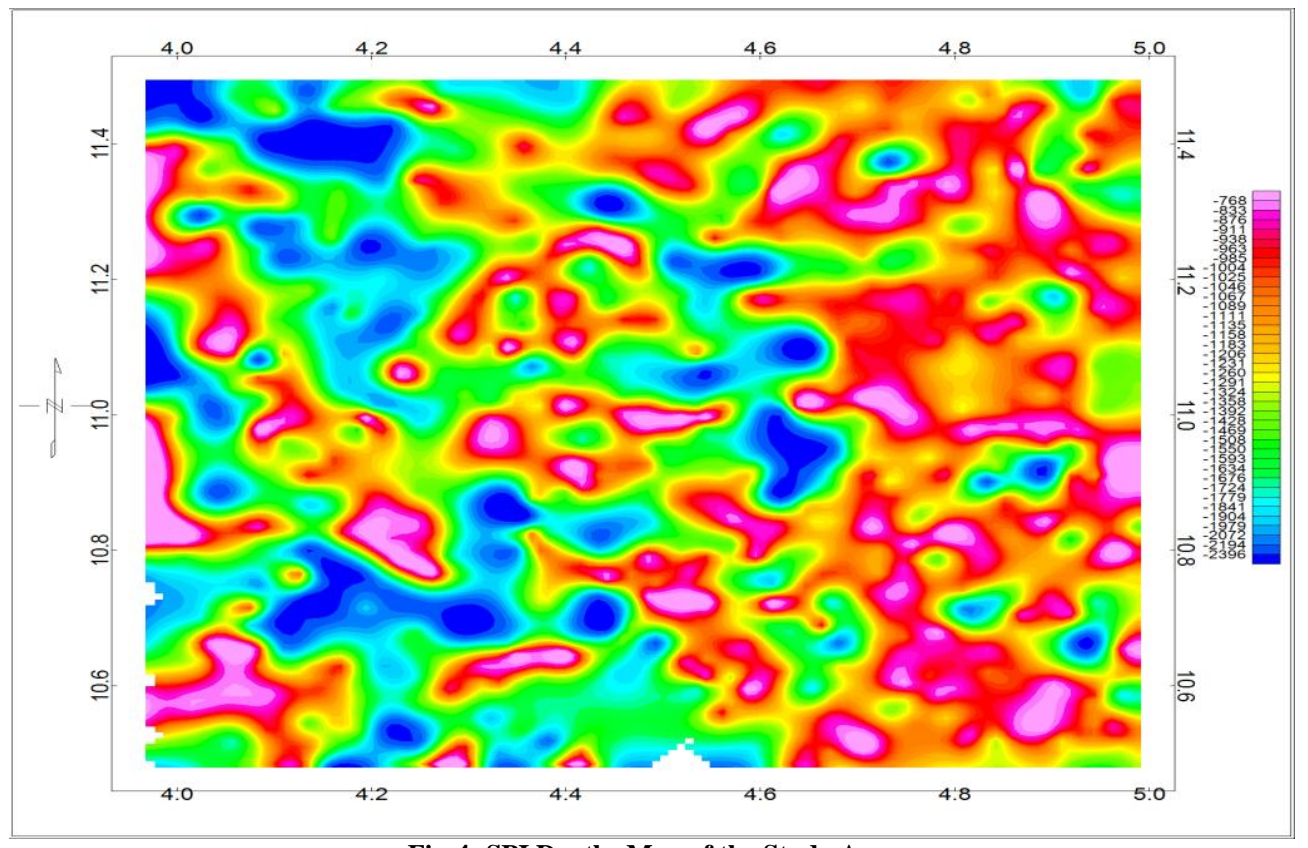

Fig-4: SPI Depths Map of the Study Area

The result of the spectral analysis of the nine sections carried out in the survey area is shown in Table-1.

Table-1: Estimated depth to the shallow (depth $)_{1}$ magnetic sources and deep $\left(\operatorname{depth}_{2}\right)$ magnetic sources in kilometers

\begin{tabular}{|l|l|l|l|l|l|}
\hline Section & Sheet Name & Longitude & Latitude & $\mathbf{Z}_{\mathbf{1}}(\mathbf{k m})$ & $\mathbf{Z}_{\mathbf{2}}(\mathbf{k m})$ \\
\hline $\mathrm{A}$ & Konkoso & 4.25 & 10.75 & 0.922 & 2.705 \\
\hline $\mathrm{B}$ & Yelwa & 4.75 & 10.75 & 0.773 & 2.601 \\
\hline $\mathrm{C}$ & Kaoje & 4.25 & 11.25 & 0.843 & 2.673 \\
\hline $\mathrm{D}$ & Shanga & 4.75 & 11.25 & 0.589 & 2.506 \\
\hline $\mathrm{E}$ & Konkoso/Yelwa & 4.50 & 10.75 & 1.169 & 2.840 \\
\hline F & Kaoje/Shanga & 4.50 & 11.25 & 1.249 & 3.111 \\
\hline $\mathrm{G}$ & Konkoso/Kaoje & 4.25 & 11.00 & 1.058 & 3.174 \\
\hline $\mathrm{H}$ & Yelwa/Shanga & 4.75 & 11.00 & 0.827 & 2.951 \\
\hline $\mathrm{I}$ & Konkoso, Yelwa Kaoje, Shanga & 4.50 & 11.00 & 1.010 & 2.824 \\
\hline
\end{tabular}

The results revealed two prominent magnetic layers being associated with all the blocks.

The first layer depth varies from $0.589 \mathrm{~km}$ to $1.249 \mathrm{~km}$ while the second layer depth varies from $2.506 \mathrm{~km}$ to $3.174 \mathrm{~km}$. The first magnetic layer is attributed to lateritic ironstones and ferruginous sandstones within and close to the surface.

On the other hand, the second magnetic layer could be attributed to magnetic rocks intrusion into the basement surface and/ or lateral discontinuities in basement susceptibilities. The second layer depth ranges from $2.506 \mathrm{~km}$ to $3.174 \mathrm{~km}$ and thus represents depth to basement in the area or the thickness of the sedimentary formations overlying the basement complex.

The depth to basement contour map showed that the basement depth deepens from the northwestern part (NW) of the study area towards Kaoje until it attains a maximum depth of $3.174 \mathrm{~km}$ and there after 
Kamba A.H et al., Saudi J Eng Technol, March. 2020; 5(3): 120-127

rises towards the flanks. The Figure thus depicts a (NESW) a subbasinal structure between Kaoje and Shanga.
The 3D surface plot of the basement depth Figure-6 clearly showed the aforementioned structure.

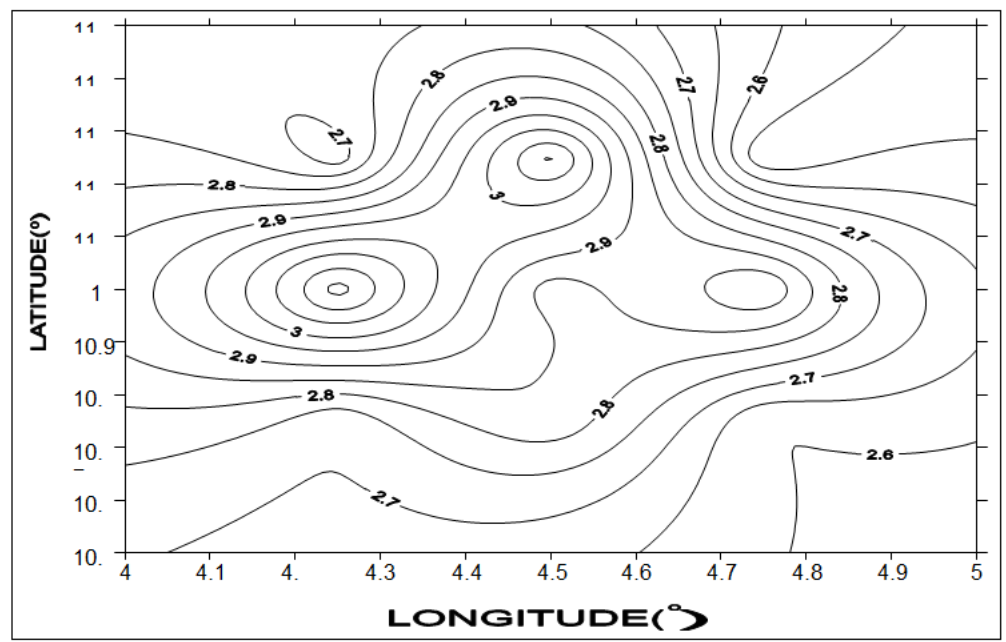

Fig-5: Contour Map of the Second Layer Depth (Contoured at an interval, 0.05 nT)

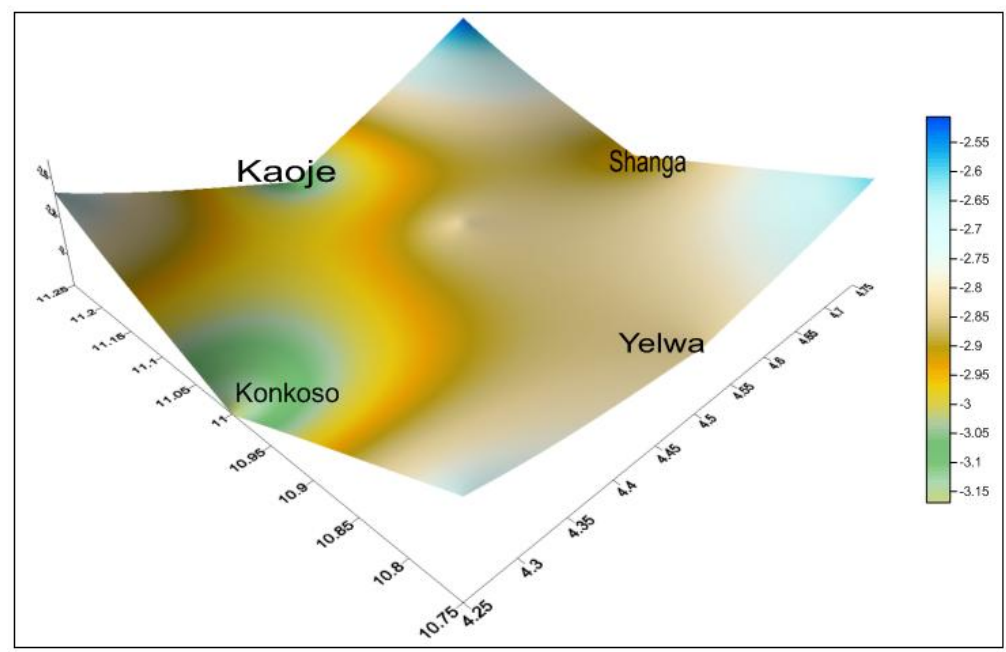

Fig-6: 3D Surface Plot of the Second Layer Depth

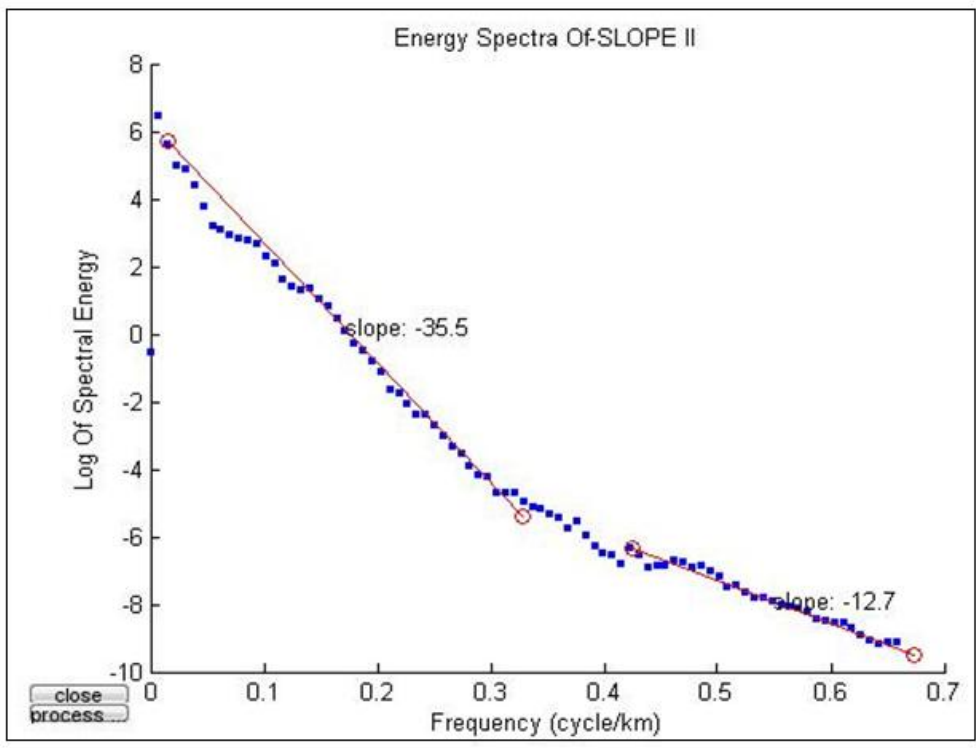

Fig-7: Energy Spectra of Block I. 


\section{CONCLUSION}

The result obtained from this study using spectral analysis method, source parameter imaging method shows that the study area has sedimentary thickness of about $3.174 \mathrm{~km}$. One important significance of this result is in its consideration of hydrocarbon prospect of the basin. If all other conditions for hydrocarbon accumulation are favourable, and the average temperature gradient of $1^{\circ} \mathrm{C}$ per $30 \mathrm{~m}$ which obtains in the Niger Delta is applicable then the maximum thickness of sediments to achieve the threshold temperature of $115^{\circ} \mathrm{C}$ for the concealment of oil formation from organic remains [17] would be $2.3 \mathrm{~km}$. The result obtained shows that the prospect for hydrocarbon accumulation may be promising.

\section{REFERENCES}

1. Dobrin, M. B. (1976). Introduction to Geophysical Prospecting, $3^{\text {rd }}$ edition, McGraw HillBook Co. Inc, New York.

2. Kearey, P.Books, M., \& Hill, I. (2004). An introduction to Geophysical Exploration. Third Edition, Black-well publishing company.

3. Cordell, L., \& Grauch, V. J. S. (1985). Mapping Basement Zones from Magnetic Data in the Sanjuan basin, New Mexican: presented at the $52^{\text {nd }}$ Annual International Meeting, Society or Exploration, Geophysicist, Dallas U.S.A.

4. Obaje, N. G. (2009).Geology and Mineral Resources of Nigeria, Lecture Note in Earth Sciences, Springer, 77-87.

5. Huntings Geology and Geophysical ltd. (1976). Airbone Magnetometer Survey Contour of Total intensity Map of Nigeria. Airbone Geophysical Series.

6. Hahn, A., Kind, E., \& Mishra, D. C. (1976). Depth Estimate of Magnetic Sources by means of Fourier amplitude Spectra, Geophy prospecting, 24:287308.

7. Udensi, E. E. (2001). Interpretation of the Total Magnetic field over the Nupe Bain in West Central
Nigeria Using aeromagnetic Data, Unpublished Ph.D. Thesis, Ahmadu Bello University, Zaria, Nigeria.

8. Spector, A. (1968). Spectral Analysis of Aeromagnetic Data: Unpublished Ph.D. Thesis, University of Toronto, Canada.

9. Spector, A., \& Grant, F. S. (1970). Statistical Models for Interpreting Aeromagnetic Data. Geophysics, 35:293-302.

10. Oppenheim, A. V., \& Schafer, R. W. (1975). Digital Signal Processing. Prentice-Hall International, Inc., N.J.

11. Kangkolo, R. (1996). A Detailed Interpretation of the Aeromagnetic field over the ManfeBasin of Nigeria and Cameroon. Unpublished Ph.D. thesis, Ahmadu Bello University, Zaria, Nigeria.

12. Thurston, J. B., \& Smith, R. S. (1997). Automatic conversion of magnetic data to depth, dip, and susceptibility contrast using the SPI Method. Geophysics, 62:807-813.

13. Nabighian, M. N. (1972). The analytical Signal of Two Dimensional Magnetic Bodies with Polygonal Cross-section. Its Properties and use for Automated Anomaly Interpretation Journal Geophysics, 37(3):507-517.

14. Hsu, S. K., Sibult, J. C., \& Shyu, C. T. (1996). High-resulation detection of geologic boundaries from potential-field anomalies; an enhanced analytic signal technique. Geophysics, 53: 31-48.

15. Reford, M. S. (1964). Rapid Calculation of Two Dimensional Magnetic Anomaly Best Parameter Set. Geoexploration, 11(1):187-193.

16. Murthy, K. S. R., \& Mishra D. C. (1980). Fourier transform of the general expression for the magnetic anomaly due to long horizontal cylinder. Geophysics, 45:1091-1093.

17. Wright, J. B., Hastings, D. A., Jones, W. B., \& Williams, H. R. (1985). Geology and Mineral Resources of West Africa. George Allen and Erwin, London: 90-120. 